\title{
BONE GRAFTS IN PERIODONTAL THERAPY
}

\author{
Sujith Sukumar, Ivo Dřizhal \\ Charles University in Prague, Faculty of Medicine and University Hospital Hradec Králové, Czech Republic: Department \\ of Dentistry
}

Summary: This article is limited to a review of bone replacement graft materials used in periodontal therapy. The source, mode of bone regeneration and the respective advantages and disadvantages of autogenous, allogenic, xenogenic and alloplastic materials are discussed.

Key words: Periodontal; Autograft; Allograft; Xenograf; Alloplast

\section{Introduction}

Maintaining the health of teeth and their supporting structures is the goal of modern periodontics. Most periodontal practices focus on prevention of disease, initial therapy and corrective surgical treatment to eliminate deep periodontal pockets. However, restoring supporting tissues to their healthy level is a critical area that offers a much more appealing, and in fact a more desired outcome for the patients. Contemporary periodontal therapy is directed towards controlling the infection and regenerating lost supporting structures. Periodontal regeneration refers to the restoration of supporting tissues of the teeth such as bone, cementum, and periodontal ligament to their original healthy levels before damage from periodontal bacteria has occurred. The key to tissue regeneration is to stimulate a cascade of healing events which, if coordinated, can result in completion of integrated tissue formation. Regeneration of supporting tooth structures is a huge step up in managing advanced periodontal disease and preventing tooth loss. Like other treatment options, it is not a panacea for all patients affected by periodontitis, but research gives us enough evidence to support the use of regenerative therapies in periodontics. Over the last decades different modalities of regenerative treatment have been developed and applied clinically. The positive effects of bone grafts and bone substitutes on the outcome of periodontal regenerative procedures are well documented. Interest in bone replacement grafts has emerged from the desire to fill an intrabony or furcation defect rather than radically resect surrounding intact bone tissue. It is assumed that the application of bone grafts would potentially manipulate the biological response into a regenerative rather than a predominantly reparative pattern of periodontal healing. In addition to bone grafting material, in cases of severe bone loss the use of barrier membranes in regenerative procedures may enhance clinical success by offering better protection and containment of the bone substitute inside the defect and disallowing fast-growing gum tissue to get into the regenerative site and interfere with the process (5). Use of barrier membranes to direct bone regeneration was first described in the context of orthopaedic research by Hurley et al., in 1959 (16). The theoretical principles basic to guided tissue regeneration (GTR) were developed by Melcher in 1976, who outlined the necessity of excluding unwanted cell lines from healing sites to allow growth of desired tissues (19). Based on positive clinical results of regeneration in periodontology research in the 1980's, research began to focus on the potential for re-building alveolar bone defects using guided bone regeneration. The first application of barrier membranes in the oral cavity was by Nyman, Lindhe, Karring and Gottlow in the context of regeneration of periodontal tissues via GTR, as an alternative to ressective surgical procedures to reduce pocket depths $(4,5,11,12,13,28)$. Both bone grafts and GTR procedures have become acceptable methods for regenerating lost attachment apparatus, but complete periodontal regeneration is rarely achieved. The recognition and efficacy of bone replacement graft materials used in combination with a barrier membrane in periodontal regeneration piloted to the scripting of this article.

\section{Bone regenerating grafts}

The use of bone grafts for reconstructing intra-osseous defects produced by periodontal disease dates back to Hegedus in 1923 (15). It was then revived in 1965 by Nabers and O'Leary (26). Now, with the introduction of advanced bone grafting techniques and the use of sophisticated bone replacement graft materials, it is possible to increase the vo- 
lume, width, and height of bone in deficient areas to regenerate the tissues supporting affected teeth and also to permit the placement of implants in their ideal positions and angulations.

A bone graft can aid in bone regeneration by three different methods, which include (i) osteogenesis, (ii) osteoconduction, and (iii) osteoinduction. Osteogenesis is the formation of new bone by the cells contained within the graft material. Osteoinduction is a chemical process in which molecules contained within the graft (bone morphogenetic proteins) convert the patient's cells into cells that are capable of forming bone. Osteoconduction is a physical effect by which the matrix of the graft forms a scaffold on which cells in the recipient site are able to form new bone (27).

\section{Classification}

Bone replacement grafts can be broadly classified into human bone and bone substitutes. This can be further classified into autografts, allografts, xenografts, and alloplasts (27).

I) Human bone

Autografts or autogenous grafts

- Extraoral

- Intraoral

Allografts or allogenic grafts

- Fresh frozen bone

- Freeze-dried bone allografts (FDBA)

- Demineralized freeze-dried bone allografts (DFDBA)

II) Bone substitutes

Xenografts or xenogenic grafts

- Bovine-derived hydroxyapatite

- Coralline calcium carbonate

Alloplasts or alloplastic grafts

- Absorbable

- Nonabsorbable

Historically, autografts were the first bone replacement grafts to be reported for periodontal applications. Allogenic freeze-dried bone was introduced to periodontics in the early 1970's, while demineralized allogenic freeze-dried bone gained wider application in the late 1980's. The introduction of xenografts and alloplasts for periodontal use occurred during the same time (27).

\section{Autografts}

Autogenous grafts are harvested from the patient, from intraoral sites (such as the maxillary tuberosity of a healing extraction site) and extraoral sites (such as the iliac crests, ribs, cranium and tibial metaphyses) $(8,31)$. The decision to use autogenous grafts necessitates consideration of the donor site, procurement technique and handling or processing of the harvested material.

Autogenous bone can be harvested intraorally, with or without processing, to yield graft materials of different forms, including cortical chips, osseous coagulum and bone blend. Many investigators have reported on the clinically successful use of intraoral autogenous grafts in the treatment of intrabony defects $(2,17,23)$. Regardless of the intraoral donor site, autografts yield regenerative responses superior to that of surgical debridement alone. Extraoral autografts such as those obtained from iliac crests have demonstrated great potential for supporting new bone growth, including clinical and histological evidence of crestal bone apposition and periodontal ligament formation. Schallhorn, Hiatt and Boyce considered the fill of crestal facial and furcation defects to be more clinically predicatble using iliac autografts than with intraoral cancellous bone (31).

Autogenous grafts are nonimmunogenic and contain osteoblasts and osteoprogenitor stem cells, which are capable of proliferating. These grafts, therefore, are osteoinductive. There are limitations to obtaining autogenous grafts, however, such as insufficient oral sites, the requirement for a second surgical site and morbidity at the donor site (30).

\section{Allografts}

Allografts, bone grafts that are harvested from one person for transplantation in another, are used widely. There are three main divisions: frozen, freeze-dried and freezedried demineralized. The possibility of disease transfer, antigenicity and the need for extensive cross-matching has disallowed the use of fresh frozen bone in modern periodontics. The evidence that freeze-drying markedly reduces the antigenicity and other health risks associated with fresh frozen bone, as well as the favorable results obtained in the field trials with freeze-dried bone allografts, have led to the extensive use of freeze-dried bone allografts in the treatment of periodontal osseous defects $(6,24)$. The use of cortical bone is recommended rather than cancellous bone allografts since cancellous bone is more antigenic and there is more bone matrix and consequently more osteoinductive components in cortical bone. Freeze-dried bone allograft is regarded as osteoconductive (10). The blockade of the effect of bone growth stimulating factors sequestered in bone matrix, like the bone morphogenic proteins, led to the development of demineralized allografts. Experimental animal studies have shown that demineralized freeze-dried bone allograft has osteogenic potential $(20,21)$. The advantages of using allografts are that the material is available in large quantities and there is no donor site within the patient. The disadvantages are that the process for preparing the graft (that is, freeze-drying and irradiating) decreases the material's integrity and osteogenic potential, and the immunological response to it may diminish its incorporation into the recipient bone. A major concern with allografts in general is the potential for disease transfer, particularly viral transmission and more particularly HIV (22). Also, there is a need for extensive cross-matching to decrease the likelihood of both graft rejection and disease transmission. 


\section{Xenografts}

Xenografts are made of naturally derived deproteinized cancellous bone from another species (such as bovine or porcine bone). The risk of transmission of diseases such as bovine spongiform encephalopathy is negligible because the bone's organic component is extracted. After the extraction of the organic components, the remaining inorganic structure provides a natural architectural matrix as well as an excellent source of calcium. The inorganic material also maintains the physical dimension of the augmentation during the remodeling phases. Bovine-derived hydroxyapatite bone replacement grafts increase the available surface area that can act as an osteoconductive scaffold due to their porosity and have a mineral content comparable to that of human bone, allowing then to integrate with the host bone. These grafts are prepared by chemical or low-heat extraction of the organic component from the bovine bone. Examples of commercially available bovine-derived bone replacement grafts are Bio-Oss ${ }^{\circledR}$ (Osteohealth Co., Shirley, NY) and Osteograf $/ N^{\circledR}$ (CeraMed Dental, LLC, Lakewood, $\mathrm{CO}$ ). Coralline calcium carbonate graft is obtained from a natural coral, genus Porites. It is hugely porous similar to that of spongy bone and so it provides a large surface area for resorption and replacement by bone $(14,34)$. An example for such type of grafts is Biocoral ${ }^{\circledR}$ (Inoteb, Saint Gonnery, France). Biocoral has a high osteoconductive potential because no fibrous encapsulation has been reported.

The main advantages of xenografts are that they are osteoconductive and readily available. A major disadvantage of bovine-derived grafts is due to the fact that it can cause disease transmission, which was evident in the case of bovine spongiform encephalopathy reported in Great Britain (27).

\section{Alloplasts}

The alloplastic grafts or synthetic bone graft substitutes as yet offer only a part solution to the management of localized bone loss. They possess some of the desired mechanical qualities of bone as well as osteoconductive properties but are largely reliant on viable periosteum/bone for their success. They primarily function as defect fillers. Ideally synthetic bone graft substitutes should be biocompatible, show minimal fibrotic reaction, undergo remodelling, and should have a similar strength and elasticity to that of the bone being replaced, thereby supporting the new bone formation. They do not induce adverse local tissue reaction, immunogenicity or systemic toxicity. They can be classified, by their ability to be bioabsorbed, into absorbable and non-absorbable.

The absorbable materials include alpha and beta tricalcium phosphate, non-sintered hydroxyapatite, and calcium sulfate. The non-absorbable materials include sintered hydroxyapatite, bioglass and $\mathrm{HTR}^{\mathrm{TM}}$ polymer. Bioceramic alloplasts are comprised mainly of calcium phosphate, with the proportion of calcium and phosphate similar to bone. The two most widely used forms are tricalcium phosphate and hydroxyapatite.

Tricalcium phosphate is a porous form of calcium phosphate. Alpha and beta tricalcium phosphate are produced similarly, although they display different resorption properties. The crystal structure of alpha tricalcium phosphate is monoclinic and consists of columns of cations while the beta tricalcium phosphate has a rhombohedral structure. The former is formed by heating the latter above $1180{ }^{\circ} \mathrm{C}$ and quenching in air to retain its structure (9). Alpha form is less stable than beta and forms the stiffer material calcium-deficient hydroxyapatite when mixed with water (32). The most commonly used form is beta tricalcium phosphate. It was one of the earliest calcium compounds to be used as a bone graft substitute. Structurally porous beta tricalcium phosphate has a compressive strength and tensile strength similar to that of cancellous bone. It undergoes resorption over a 6-18 month period. Unfortunately, the replacement of beta tricalcium phosphate by bone does not occur in an equitable way. That is, there is always less bone volume produced than the volume of the graft material resorbed. For this reason, the clinical use of beta tricalcium phosphate has been rather as an adjunctive with other less resorbable bone graft substitutes or as an expander for autogenous bone graft. Examples of commercially available beta tricalcium phosphate graft material are Synthograft $^{\mathrm{TM}}$ (Bicon, Boston MA, USA) and Cerasorb ${ }^{\circledR}$ (Curasan Pharma GmbH, Kleinostheim, Germany).

The next calcium phosphate preparation to become available was synthetic hydroxyapatite in the 1970's. It is available in resorbable and non-resorbable forms. Whether synthetic hydroxyapatite is resorbable or non-resorbable depends on the temperature at which it is prepared. High-temperature preparation (sintering) of hydroxyapatite results in a nonresorbable, nonporous, dense material (18). Dense non-resorbable hydroxyapatite grafts are osteophilic, osteoconductive and act primarily as inert biocompatible bone defect fillers. Histologically, new attachment is not achieved but a more stable clinical improvement is attained than with open flap debridement alone in the treatment of periodontal osseous defects $(7,35)$. The resorbable form is processed at a low temperature. As it resorbs, a readily available source of calcium becomes available in sites that have osteogenic potential (29). Its reported advantage is the slow resorption rate, allowing it to act as a mineral reservoir and at the same time acting as a scaffold for bone replacement (33). It is marketed in different trade names like Osteogen ${ }^{\circledR}$ (Impladent, NY, USA).

Calcium sulfate or plaster of Paris was first documented as being used for fracture treatment by the Arabs in the 10 th century, who would surround the affected limb in a tub of plaster. In 1852 a Dutch army surgeon named Mathysen incorporated plaster into the bandageable form which we are familiar with today (25). Calcium sulfate is thought to act as an osteoconductive matrix for the in- 
growth of blood vessels and associated fibrogenic and osteogenic cells. For this to occur, it is critically important that the implanted calcium sulfate is adjacent to viable periosteum or endosteum (3). Over a period of 5-7 weeks, calcium sulfate is reabsorbed by a process of dissolution (1). Currently, medical grade calcium sulfate impregnated with tobramycin is commercially available $\left(\right.$ Osteoset $^{\circledR}$; Wright Medical Technology, Arlington, TN, USA). Calcium sulfate in its set form has a compressive strength greater than cancellous bone and a tensile strength slightly less than cancellous bone. Calcium sulfate, however, requires a dry environment to set and if it is re-exposed to moisture it tends to soften and fragment. For this reason it has no reliable mechanical properties in vivo and its application should be limited to a contained area. Hence the primary use of calcium sulfates should be as a bone void filler.

Bioactive glass is a silicone-based, osteoconductive material that binds to bone through the formation of carbonated hydroxyapatite. When exposed to tissue fluids, bioactive glasses are covered by a double layer composed of silica gel and a calcium-phosphorous rich (apatite) layer. The later promotes adsorption and concentration of proteins utilized by osteoblasts to form a mineralized extracellular matrix. It is believed that these bioactive properties guide and promote osteogenesis, allowing rapid formation of bone. Examples of bioactive glasses comercially available are Perioglas ${ }^{\circledR}$ (Block Drug Co., NJ, USA) and Bio$\operatorname{gran}^{\circledR}$ (Orthovita, PA, USA).

HTR $^{\mathrm{TM}}$ synthetic bone (Bioplant, CT, USA) is a biocompatible microporous composite of methylmethacrylate and hydroxymethylmethacrylate polymers and calcium hydroxide. HTR stands for hard tissue replacement. Its hydrophilicity enhances clotting, and its negative particle surface charge allows adherence to bone. It appears to serve as a scaffold for bone formation when in close contact with alveolar bone. Histological evidence of new bone formation on $\mathrm{HTR}^{\mathrm{TM}}$ particles has been reported.

Alloplasts can be mixed with autogenous grafts or allografts in the management of large structural defects. Some alloplastic materials are mixed together to achieve superior results. Fortoss ${ }^{\circledR}$ Vital (Biocomposites, Staffordshire, UK) is such a mixture of beta tricalcium phosphate and calcium sulfate. This can be used for guided tissue regeneration without an additional membrane as calcium sulfate serves the purpose of a membrane.

\section{Conclusion}

Bone grafting is now a well-recognized choice in the treatment of periodontal osseous defects, especially when used along with barrier membranes. Various types of bone grafts and also their combinations are used with varying degrees of success. Rapid developments in this particular field are leading us towards achieving the ultimate goal in periodontal therapy, which is the regeneration of lost periodontal tissues. Although complete regeneration is now a distant dream, the use of bone grafts enabled us to make slow but sure progress. Autografts are still considered the ideal grafts except for the difficulty in obtaining them. So with the source limitations of autogenous bone and concerns regarding allogenic bone, the role of bone substitutes will likely increase. The future of bone grafts is likely to lie in the industrially manufactured biomaterials in combination with laboratory-grown cells developed by tissue-engineering.

\section{Acknowledgement}

This paper has been supported by the research project FN HK MZO 00179906.

\section{References}

1. Bell WH. Resorption rates of bone and bone substitutes. Oral Surg. 1964;17: $650-7$.

2. Carraro JJ, Sznajder N, Alonso CA. Intraoral cancellous bone autografts in the treatment of intrabony pockets. J. Clin. Periodontol 1976;3:104-9.

3. Coetzee AS. Regeneration of bone in the presence of calcium sulfate. Arch Otolaryngol 1980;106:405-9.

4. Dřizhal I, Červinka M, Taha M, Strnad L. Řizená tkáňová regenerace - uplatnění v parodontologii. Quintessenz - Parodontologie 2001;2:18-25.

5. Fassmann A. Řizená tkáňová a kostní regenerace ve stomatologii. Praha: Grada Publishing, 2002:13-14.

6. Friedlaender GE, Strong DM, Sell KW. Studies on the antigenicity of bone. Freeze-dried and deep frozen bone allografts in rabbits. J Bone Joint Surg Am 1976;58:854-8

7. Fucini SE, Quintero G, Gher ME, Black BS, Richardson AC. Small versus large particles of demineralized freeze dried bone allografts in human intrabony periodontal defects. J Peridontol 1993;64:844-7.

8. Garrett S, Bogle G. Periodontal regeneration with bone grafts. Curr Opin Periodontol 1994:168-77.

9. Ginebra MP, Fernández E, Driessens FCM, Planell JA. Modeling of the hydrolysis of $\alpha$-Tricalcium phosphate. J Am Ceram Soc 2004;82:2808-12.

10. Goldberg VM, Stevenson S. Natural history of autografts and allografts. Clin Orthop Relat Res 1987;225:7-16.

11. Gottlow J, Nyman S. Barrier membranes in the treatment of periodontal defects. Curr Opin Periodontol 1996;3:140-8.

12. Gottlow J, Nyman S, Lindhe J. New attachment formation as a result of controlled tissue regeneration. J Clin Periodontol. 1984;11:494-503.

13. Gottlow J, Nyman S, Lindhe J, Karring T, Wennström J. New attachment formation in human periodontium by guided tissue regeneration. J Clin Periodontol. 1986;13:604-15

14. Guillemin G, Patat JL, Fournie J, Chetail M. The use of coral as a bone graft substitute. J Biomed Mater Res 1987;21:557-67.

15. Hegedus Z. The rebuilding of the alveolar process by bone transplantation. Dent Cosmos 1923;65:736

16. Hurley LA, Stinchfield FE, Basset AL, Lyon WH. The role of soft tissues in osteogenesis. J Bone Joint Surg 1959;41A:1243-54.

17. Kiyokawa K, Kiyokawa M, Hariya Y, Fujii T, Tai Y. Regenerative treatment of serious periodontosis with grafting of cancellous iliac bone and gingival flaps and replanting of patients' teeth. J Craniofac Surg. 2002;13:375-81.

18. Klein CP, Driessen AA, de Groot K, van den Hooff A. Biodegradation behaviour of various calcium phosphate materials in bone tissue. J Biomed Mater Res $1983 ; 17: 769-84$.

19. Melcher AH. On the repair potential of periodontal tissues. J Periodontol 1976; 47:256-60.

20. Mellonig J, Bowers G, Bailey R. Comparison of bone graft materials. I. New bone formation with autografts and allografts: A histological evaluation. J Periodontol 1981:52:297-302.

21. Mellonig J, Bowers G, Bailey R. Comparison of bone graft materials. I. New bone formation with autografts and allografts determined by Strontium 85. J Periodontol 1981;52:291-6.

22. Mellonig JT, Prewett AB, Moyer MP. HIV inactivation in a bone allograft. J Periodontol 1992;63:979-83.

23. Mellonig JT. Autogenous and allogeneic bone grafts in periodontal therapy. Crit Rev Oral Biol Med 1992;3:333-52.

24. Mellonig JT. Freeze-dried bone allografts in periodontal reconstructive surgery. Dent Clin North Am 1991:35:505-20.

25. Moore WR, Graves SE, Bain GI. Synthetic bone graft substitutes. ANZ J. Surg. 2001;71:354-61. 
26. Nabers CL, O'Leary TJ. Autogenous bone transplants in the treatment of osseous defects. J Periodontol 1965;36:5-14.

27. Nasr HF, Aichelmann-Reidy ME, Yukna RA. Bone and bone substitutes. Pe riodontology 2000 1999;19:74-86.

28. Nyman S, Lindhe J, Karring T, Rylander H. New attachment following surgica treatment of human periodontal disease. J Clin Periodontol 1982;9:290-96.

29. Ricci JL, Blumenthal NC, Spivak JM, Alexander H. Evaluation of a low temperature calcium phosphate particulate implant material: physical-chemical properties and in vivo bone response. J Oral Maxillofac Surg 1992;50:969-78

30. Rosenberg E, Rose LF. Biologic and clinical considerations for autografts and allografts in periodontal regeneration therapy. Dent Clin North Am 1998;42: 467-90.
31. Schallhorn RG, Hiatt WH, Boyce W. Iliac transplants in periodontal therapy. J Periodontol 1970;41:566-80.

32. TenHuisen KS, Brown PW. Formation of calcium-deficient hydroxyapatite from alpha-tricalcium phosphate. Biomaterials 1998;19:2209-17.

33. Wagner JR. Clinical and histological case study using resorbable hydroxyapatite for the repair of osseous defects prior to endosseous implant surgery. J Oral Implantol 1989;15:186-92

34. Yukna RA. Clinical evaluation of coralline calcium carbonate as a bone replacement graft material in human periodontal osseous defects. J Peridontol 1994; 65:177-85.

35. Yukna RA, Mayer ET, Amos SM. 5-year evaluation of durapatite ceramic alloplastic implants in periodontal osseous defects. J Periodontol 1989;60:544-51.

Submitted September 2008.

Accepted December 2008.

\section{Corresponding author:}

Dr. Sujith Sukumar, BDS, University Hospital Hradec Králové, Department of Dentistry, Sokolská 581, 50005 Hradec Králové, Czech Republic; e-mail: docsujith@gmail.com 